\title{
Surgery following neoadjuvant chemotherapy for non-small-cell lung cancer patients with unexpected persistent pathological $\mathbf{N} 2$ disease
}

\author{
XUE-FEI HU* , LIANG DUAN**, GE-NING JIANG, CHANG CHEN and KE FEI \\ Department of General Thoracic Surgery, Shanghai Pulmonary Hospital, \\ Tongji University School of Medicine, Shanghai 200433, P.R. China
}

Received December 17, 2014; Accepted February 25, 2015

DOI: $10.3892 / \operatorname{mco} .2015 .706$

\begin{abstract}
Patients with mediastinal lymph node (LN) downstaging following neoadjuvant chemotherapy exhibit improved outcomes compared with patients with persistent N2 disease. The aim of this study was to compare clinicopathological characteristics and survival between patients with unexpected and expected persistent $\mathrm{N} 2$ disease following surgery for non-small-cell lung cancer (NSCLC). This retrospective analysis included 348 patients with NSCLC who underwent surgery following chemotherapy at the Shanghai Pulmonary Hospital, Tongji University School of Medicine, between 1995 and 2012. According to the results of the imaging examinations and postoperative pathology, the patients were divided into three groups, namely groups I (nodal downstaging, pN0-1), II (expected persistent N2 disease) and III (unexpected persistent $\mathrm{N} 2$ disease). The rates of overall survival (OS) and disease-free survival(DFS) were estimated by the Kaplan-Meier method. Univariate and multivariate analyses were performed to identify the independent risk factors for OS and DFS. The mortality rate was $1.1 \%$ during the postoperative period. Perioperative complications occurred in 45 patients (12.9\%). The 5-year OS rate was 32.2, 6.3 and $25.9 \%$ in groups I, II and III, respectively (group I vs. III, $\mathrm{P}=0.023$; and group III vs. II, $\mathrm{P}<0.001)$. The 5-year DFS rate was 30.1, 5.1 and $22.4 \%$ in groups I, II and III, respectively (group I vs. III, P=0.012; and group III vs. II, $\mathrm{P}<0.001)$. Grouping, predicted forced expiratory volume in $1 \mathrm{sec}, \mathrm{N}$ downstaging and skip N2 metastasis were identified as independent predictive factors associated with
\end{abstract}

Correspondence to: Dr Chang Chen or Dr Ke Fei, Department of General Thoracic Surgery, Shanghai Pulmonary Hospital, Tongji University School of Medicine, 507 Zhengmin Road, Shanghai 200433, P.R. China

E-mail: changchenc@hotmail.com

E-mail: ffeik@yahoo.cn

*Contributed equally

Key words: neoadjuvant chemotherapy, unexpected persistent $\mathrm{N} 2$ disease, surgery, non-small-cell lung cancer
OS, whereas the independent risk factors associated with DFS were grouping and $\mathrm{N}$ downstaging. Patients with unexpected persistent N2 disease exhibited better survival compared with those with expected persistent N2 disease. Surgery following chemotherapy remains the optimal approach for a proportion of patients with persistent $\mathrm{N} 2$ disease.

\section{Introduction}

Mediastinal lymph node (LN) metastasis is one of the most significant prognostic factors in patients with non-small-cell lung cancer (NSCLC) and accurate $\mathrm{N}$ staging is a crucial step prior to decision making regarding the treatment of NSCLC patients (1). However, the optimal treatment approach for NSCLC patients with operable N2 disease remains controversial. According to a previous study, direct surgery for patients with clinically apparent N2 disease achieved a long-term survival rate of $<10 \%$ of (2). However, certain phase II trials and a limited number of phase III trials suggested improved long-term survival for NSCLC patients with N2 disease treated with neoadjuvant therapy followed by surgical resection, compared with those undergoing surgery alone (3-7). Additionally, Pataer et al reported that the histopathological response to neoadjuvant chemotherapy was significantly associated with long-term overall survival (OS) in NSCLC patients with $\mathrm{N} 2$ disease (8). In a prospective phase II study evaluating neoadjuvant cisplatin and docetaxel, the 3 -year survival rate was $61 \%$ in patients with pathologically negative mediastinal LNs, compared with $11 \%$ in those with persistent N2 disease, following chemotherapy (9). Despite meticulous efforts to assess the nodal status, unexpected persistent $\mathrm{N} 2$ disease following induction (neoadjuvant) chemotherapy may be identified following surgical treatment for NSCLC, as false-negative results are intrinsic to the preoperative staging workup. The fact that persistent N2 disease was unexpectedly detected in surgical specimens of patients with clinical N0-1 disease following neoadjuvant chemotherapy suggests that the pathological extent of N2 disease may be microscopic rather than macroscopic in such cases (10). However, the optimal treatment selection for this subgroup of patients remains debated upon and the role of surgery following induction therapy has not yet been clearly determined. 
We reviewed our experience with patients treated with neoadjuvant chemotherapy for N2 NSCLC followed by surgical resection. The objective of this study was to compare the clinicopathological characteristics and survival outcomes between patients with unexpected persistent $\mathrm{N} 2$ disease (clinical N0-1, pathological N2) and those with expected persistent $\mathrm{N} 2$ disease (clinical N2, pathological N2) undergoing surgery following neoadjuvant chemotherapy for NSCLC.

\section{Patients and methods}

Patient population. The medical records of 392 consecutive patients with a pathological diagnosis of NSCLC who received neoadjuvant chemotherapy at the Department of General Thoracic Surgery, Shanghai Pulmonary Hospital (Shanghai, China) between January, 1995 and December, 2012 were reviewed. All the patients underwent contrast-enhanced thoracic computed tomography $(\mathrm{CT})$ or ${ }^{18} \mathrm{~F}$-fluorodeoxyglucose (FDG)-positron emission tomography (PET)/CT prior to surgery. Additional routine pretreatment evaluations included chest radiography, abdominal ultrasonography or CT scan, brain magnetic resonance imaging or CT scan, cardiopulmonary function tests and whole-body radionuclide bone scanning. Mediastinoscopy or endobronchial ultrasonography-guided transbronchial needle aspiration biopsy were routinely performed on patients with bulky mediastinal LNs on CT (short-axis diameter $>1.5 \mathrm{~cm}$ ). The patients were staged according to the seventh edition of the TNM classification (11).

The inclusion criteria were patients with pathological $\mathrm{N} 2$ disease prior to treatment and administration of neoadjuvant chemotherapy. The chemotherapeutic regimens included platinum in combination with gemcitabine, vinorelbine, paclitaxel or docetaxel. The exclusion criteria were patients with superior sulcus tumors, lack of indications for surgery, treatment with induction radiotherapy and palliative surgery. Finally, a total of 348 patients were enrolled in this study.

Response to neoadjuvant chemotherapy. After two cycles of neoadjuvant chemotherapy, the response to treatment was classified according to the World Health Organization criteria by CT scan and bronchoscopy (12) as follows: Complete response, disappearance of all disease on radiographic and bronchoscopic (when performed) examination; partial response, $>50 \%$ reduction in the volume of all measurable lesions; stable disease, no detectable change in tumor volume of all lesions or change in the size of all measured lesions between a $50 \%$ reduction and a $25 \%$ increase, with no additional disease detected; progressive disease, increase of $>25 \%$ of all measured lesions or appearance of new lesions. Complete and partial response are both classified as objective response. Only patients with objective response or stable disease were considered eligible for surgery.

Definitions and grouping. A resection was considered as complete (R0) when there was no residual tumor at the bronchial or vascular margins and no residual LN disease. Nodal downstaging was defined as resected mediastinal LNs free of gross and microscopic disease. Clinical nodal downstaging was defined as a long-axis diameter of mediastinal $\mathrm{LNs}<1 \mathrm{~cm}$ on chest CT or negative PET/CT findings; pathological nodal downstaging was defined as absence of microscopic disease in the resected mediastinal nodes.

According to the definition of clinical or pathological nodal downstaging, all the enrolled cases were assigned into three study groups as follows: Group I, nodal downstaging (pN0-1); group II, no nodal downstaging (expected persistent N2 disease); and group III, clinical nodal downstaging without pathological nodal downstaging (unexpected persistent N2 disease).

Surgical procedures. All the patients received R0 resection. The surgical procedures included lobectomy, bilobectomy, sleeve resection and pneumonectomy. Systemic lymphadenectomy was defined as removal of at least three mediastinal stations and $>10$ nodes, additional to the resection of hilar nodes (13). Systemic lymphadenectomy was mandatory for all the patients in this study. Mediastinal LN dissection consisted of en bloc resection of all nodes at stations $2 \mathrm{R}, 4 \mathrm{R}, 7,8,9$ and $10 \mathrm{R}$ for right-sided tumors and nodes at stations $4 \mathrm{~L}, 5,6,7,8,9$ and $10 \mathrm{~L}$ for left-sided tumors. Bronchial stumps underwent routine frozen sections to ensure microscopically tumor-free margins in all the cases.

Postoperative treatment and follow-up. Adjuvant chemotherapy was administered to the patients included in this study and mediastinal regional radiotherapy was performed in patients with persistent $\mathrm{N} 2$ disease, provided they were able to tolerate additional treatments. The patients were regularly evaluated by CT every 6 months for the first 2 years after surgery and every 12 months thereafter.

All the patients were followed up by trained staff every 6 months, by phone or e-mail. All patient information regarding survival, cancer recurrence or metastasis and cause of death were recorded. In the present study, the endpoint of follow-up was December, 2012, with a mean follow-up of 55 months.

Statistical analysis. Numerical data are expressed in terms of frequency, mean and standard deviation and categorical variables as percentages. The Chi-square test or Fisher's exact test were used to compare proportional data. One-way analysis of variance or the Kruskal-Wallis test, depending on the normality of distribution, were used to compare continuous variables among the three groups. Survival curves were constructed using the Kaplan-Meier method and were compared univariately using the log-rank test. The Cox-regression test was used for multivariate analysis of survival. All the statistical tests were two-sided, with a significance level set at 0.05 .

\section{Results}

Patient characteristics. The patient characteristics are summarized in Table I. The study included 273 men and 75 women, with a mean age of 55 years (range, 27-78 years). The most common comorbidities were chronic obstructive pulmonary disease in 79 (22.7\%) and cardiovascular diseases in 41 (11.8\%) patients. A total of 264 (75.9\%) patients underwent invasive staging of the mediastinum by mediastinoscopy or endobronchial ultrasonography-guided transbronchial needle aspiration biopsy, whereas $84(24.1 \%)$ were staged by percutaneous lung puncture biopsy and CT or PET/CT scan. 
Table I. Clinical characteristics of the patients $(n=348)$.

Variables

Patient no. (\%)

\section{Groups}

I

II

III

Gender

Male

Female

Age (years)

$\leq 60$

$>60$

Smoking history

Yes

No

$211(60.6)$

79 (22.7)

58 (16.7)

$273(78.4)$

$75(21.6)$

$189(54.3)$

$159(45.7)$

249 (71.6)

99 (28.4)

Predicted FEV1

$\leq 60 \%$

$>60 \%$

40 (11.5)

$308(88.5)$

Clinical T stage

T1

T2

T3

T4

$34(9.8)$

$196(56.3)$

$92(26.4)$

$26(7.5)$

Comorbidities

Yes

$124(35.6)$

No

$224(64.4)$

Clinical N2 levels

Single

Multiple

$298(85.6)$

$50(14.4)$

Clinical stage

IIIA

IIIB

Imaging response

Objective response

Stable disease

$264(75.9)$

$84(24.1)$

Type of operation

Lobectomy

$181(52.0)$

$55(15.8)$

$112(32.2)$

Pneumonectomy

$100(28.7)$

$195(56.0)$

$43(12.4)$

10 (2.9)

Others

$211(60.6)$

$137(39.4)$

No

$60(17.2)$

Yes

$288(82.8)$
The tumors were considered fully resectable in all the patients. More patients in group I underwent lobectomy compared with groups II and III $(\mathrm{P}<0.001)$ and fewer patients in group II achieved an objective response compared with groups I and III $(\mathrm{P}<0.001)$. As regards histological subtype, the percentage of adenocarcinoma was 28.9, 20.3 and $39.7 \%$ in groups I, II and III, respectively $(\mathrm{P}=0.002)$. In addition, a lower proportion of group II patients exhibited a higher clinical $\mathrm{T}$ stage compared with the other two groups $(\mathrm{P}=0.002)$ (Table II).

Outcomes of neoadjuvant chemotherapy. All the chemotherapeutic regimens contained platinum in combination with gemcitabine in 135 cases $(38.8 \%)$, vinorelbine in $58(16.7 \%)$, paclitaxel in $31(8.9 \%)$ and docetaxel in $124(35.6 \%)$ cases (data not shown). Following completion of the neoadjuvant chemotherapy, imaging was repeated in all the patients (CT in $82 \%$ and PET/CT in $18 \%$ of the patients). In total, 264 patients $(75.9 \%)$ exhibited a radiographic objective response to chemotherapy (31 complete and 233 partial responses), whereas 84 cases exhibited stable disease.

Survival. The mortality rate was $1.1 \%$ during the postoperative period $(n=4)$. The causes of death included pneumonia $(n=1)$, cardiovascular disease $(n=2)$ and acute respiratory distress syndrome $(n=1)$. Perioperative complications occurred in 45 patients $(12.9 \%)$. The median duration of follow-up for the entire cohort was 55.2 months (range, 1-100 months). A total of 18 patients were lost to follow-up. At the end of the follow-up period, 137 patients $(39.4 \%$ ) had died (17 from tumor-unrelated causes), 165 patients (47.4\%) remained alive and free of disease and $46(13.2 \%)$ remained alive with recurrence. The 5-year OS rate was $32.2,6.3$ and $25.9 \%$ in groups I, II and III, respectively (group I vs. III, P=0.023; and group III vs. II, $\mathrm{P}<0.001$ ) (Fig. 1A). Patients with persistent $\mathrm{N} 2$ disease had a lower 5-year OS compared with that of patients whose disease was downstaged (14.6 vs. 32.2\%, respectively; $\mathrm{P}<0.001$ ) (Fig. 1B). Recurrence occurred in 166 patients $(47.7 \%)$. The pattern of recurrence was locoregional in 69 patients, distant in 71 and both in 26. The 5-year disease-free survival (DFS) rate was 30.1, 5.1 and $22.4 \%$ in groups I, II and III, respectively (group I vs. III, $\mathrm{P}=0.012$; and group III vs. II, $\mathrm{P}=0.027$ ) (Fig. $2 \mathrm{~A}$ ). Patients with persistent $\mathrm{N} 2$ disease had a lower 5-year DFS compared with that of patients whose disease was downstaged (12.5. vs. $30.7 \%$, respectively; $\mathrm{P}<0.001$ ) (Fig. $2 \mathrm{~B}$ ).

Multivariate analysis of $O S$ and DFS. All the variables were included in the multivariate analysis. The results are summarized in Tables III and IV. Grouping $(\mathrm{P}=0.016)$, predicted forced expiratory volume in $1 \mathrm{sec}(\mathrm{P}=0.035)$, $\mathrm{N}$ downstaging $(\mathrm{P}=0.013)$ and skip $\mathrm{N} 2$ metastasis $(\mathrm{P}=0.003)$ were identified as independent predictive factors associated with OS, whereas grouping $(\mathrm{P}=0.037)$ and $\mathrm{N}$ downstaging $(\mathrm{P}=0.032)$ were found to be independent risk factors associated with DFS.

\section{Discussion}

The optimal treatment for resectable N2 NSCLC remains controversial. Neoadjuvant chemotherapy was shown to

FEV1; forced expiratory volume in $1 \mathrm{sec}$; CT; computed tomography. 
Table II. Comparison of main clinicopathological characteristics among the three groups.

\begin{tabular}{|c|c|c|c|c|}
\hline \multirow[b]{2}{*}{ Variables } & \multicolumn{3}{|c|}{ Patient no. $(\%)$} & \multirow[b]{2}{*}{ P-value } \\
\hline & Group I (n=211) & Group II (n=79) & Group III (n=58) & \\
\hline Gender & & & & 0.343 \\
\hline Male & $171(81.0)$ & $59(74.7)$ & $43(74.1)$ & \\
\hline Female & $40(19.0)$ & $20(25.3)$ & $15(25.9)$ & \\
\hline Age (years) & & & & 0.707 \\
\hline$\leq 60$ & $113(53.6)$ & $46(58.2)$ & $30(51.7)$ & \\
\hline$>60$ & $98(46.4)$ & $33(41.8)$ & $28(48.3)$ & \\
\hline Smoking history & & & & 0.738 \\
\hline Yes & $148(70.1)$ & $59(74.7)$ & $42(72.4)$ & \\
\hline No & $63(29.9)$ & $20(25.3)$ & $16(27.6)$ & \\
\hline Predicted FEV1 & & & & 0.106 \\
\hline$\leq 60 \%$ & $27(12.8)$ & $4(5.1)$ & $9(15.5)$ & \\
\hline$>60 \%$ & $184(87.2)$ & $75(94.9)$ & $49(84.5)$ & \\
\hline Clinical T stage & & & & 0.002 \\
\hline $\mathrm{T} 1$ & $19(9.0)$ & $11(13.9)$ & $4(6.9)$ & \\
\hline $\mathrm{T} 2$ & $131(62.1)$ & $32(40.5)$ & $33(56.9)$ & \\
\hline T3 & $41(19.4)$ & $33(41.8)$ & $18(31.0)$ & \\
\hline $\mathrm{T} 4$ & $20(9.5)$ & $3(3.8)$ & $3(5.2)$ & \\
\hline Comorbidities & & & & 0.481 \\
\hline Yes & $80(37.9)$ & $24(30.4)$ & $20(34.5)$ & \\
\hline No & $131(62.1)$ & $55(69.6)$ & $38(65.5)$ & \\
\hline Clinical N2 levels & & & & 0.087 \\
\hline Single & $187(88.6)$ & $62(78.5)$ & $49(84.5)$ & \\
\hline Multiple & $24(11.4)$ & $17(21.5)$ & $9(15.5)$ & \\
\hline Clinical stage & & & & 0.252 \\
\hline IIIA & $192(91.0)$ & $76(96.2)$ & $55(94.8)$ & \\
\hline IIIB & $19(9.0)$ & $3(3.8)$ & $3(5.2)$ & \\
\hline Imaging response & & & & $<0.001$ \\
\hline Objective response & $199(94.3)$ & $7(8.9)$ & $58(100.0)$ & \\
\hline Stable disease & $12(5.7)$ & $72(91.1)$ & $0(0.0)$ & \\
\hline Type of operation & & & & $<0.001$ \\
\hline Lobectomy & $132(62.6)$ & $27(34.2)$ & $22(37.9)$ & \\
\hline Bilobectomy & $37(17.5)$ & $11(13.9)$ & $7(12.1)$ & \\
\hline Pneumonectomy & $42(19.9)$ & $41(51.9)$ & $29(50.0)$ & \\
\hline Histology & & & & 0.002 \\
\hline Adenocarcinoma & $61(28.9)$ & $16(20.3)$ & $23(39.7)$ & \\
\hline Squamous cell carcinoma & $127(60.2)$ & $40(50.6)$ & $28(48.3)$ & \\
\hline Adenosquamous carcinoma & $17(8.1)$ & $20(25.3)$ & $6(10.3)$ & \\
\hline Others & $6(2.8)$ & $3(3.8)$ & $1(1.7)$ & \\
\hline $\mathrm{N}$ downstaging & & & & $<0.001$ \\
\hline Yes & $211(100.0)$ & $0(0.0)$ & $0(0.0)$ & \\
\hline No & $0(0.0)$ & $79(100.0)$ & $58(100.0)$ & \\
\hline Skip N2 metastasis & & & & $<0.001$ \\
\hline Yes & $0(0.0)$ & $32(40.5)$ & $28(48.3)$ & \\
\hline No & $211(100.0)$ & $47(59.5)$ & $30(51.7)$ & \\
\hline
\end{tabular}

FEV1; forced expiratory volume in $1 \mathrm{sec}$; CT, computed tomography.

improve survival compared with surgery alone in certain randomized trials $(7,14,15)$. However, these results were not confirmed by other randomized studies $(16,17)$. Additionally, a potential role for radiation therapy in the treatment of $\mathrm{N} 2$ disease has been considered. A study by van Meerbeeck et al reported no differences in survival between surgery and radiation 
$\mathbf{A}$

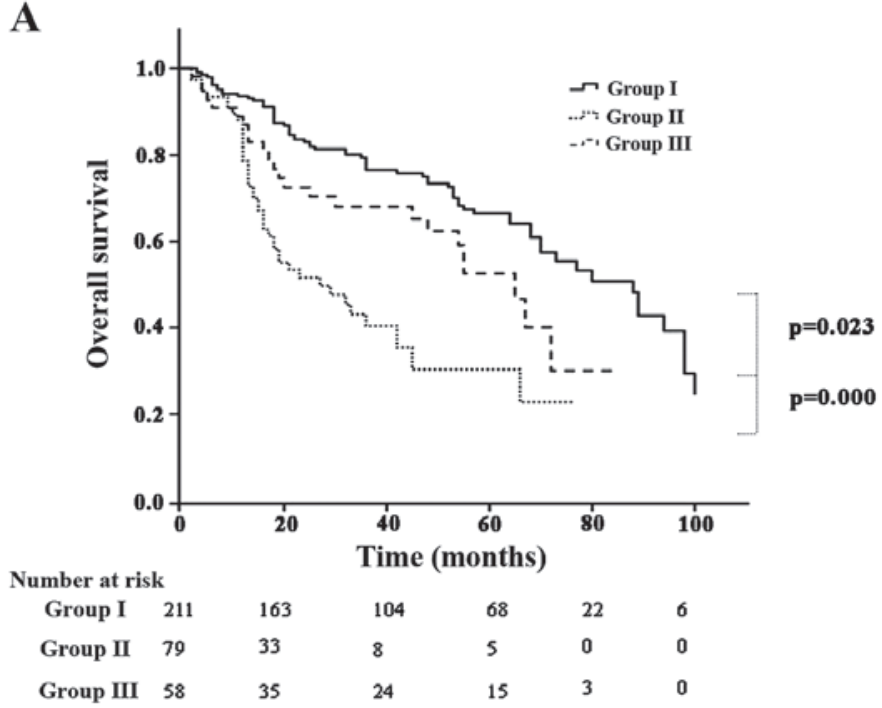

B

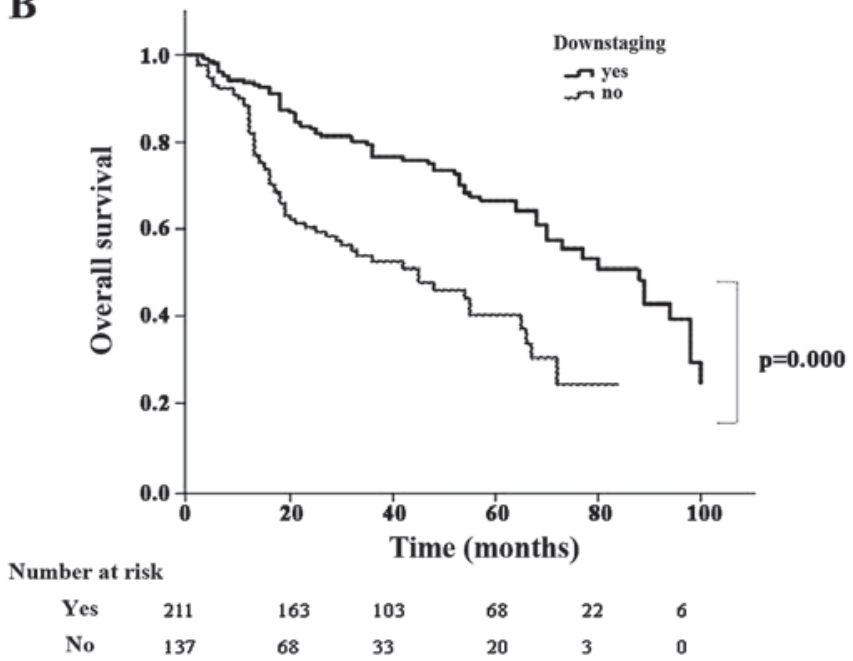

Figure 1. (A) Overall survival according to subgroup; (B) overall survival according to N downstaging.

A

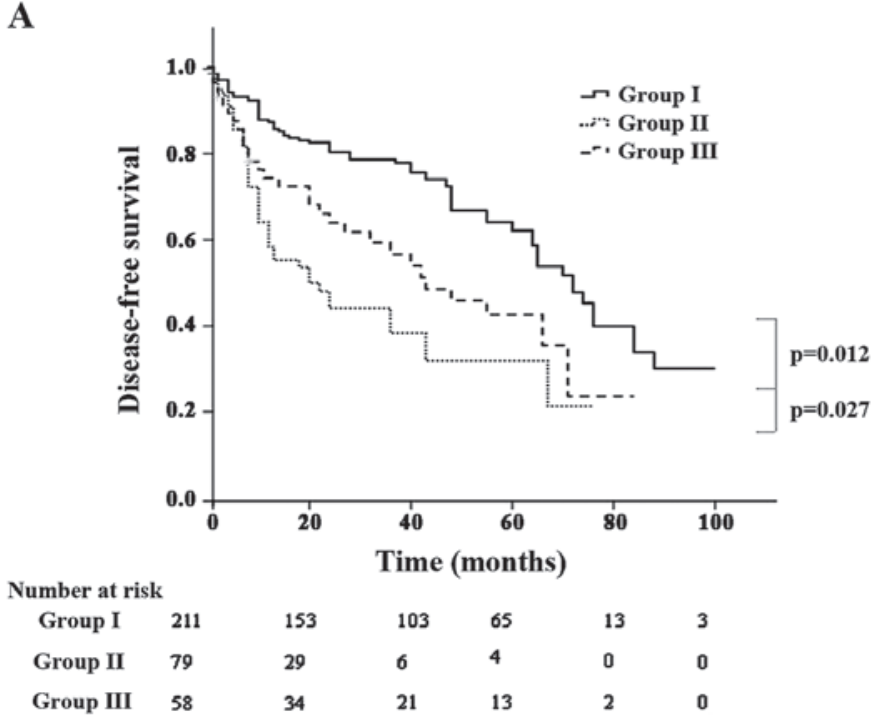

B

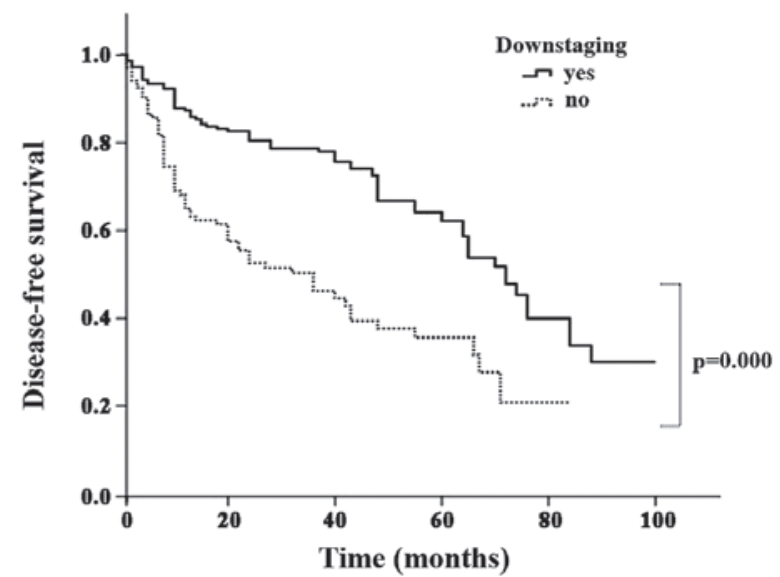

Number at risk

$\begin{array}{lllllll}\text { Yes } & 211 & 153 & 103 & 65 & 13 & 3 \\ \text { No } & 137 & 63 & 27 & 17 & 2 & 0\end{array}$

Figure 2. (A) Disease-free survival according to subgroup; (B) disease-free survival according to N downstaging.

therapy following induction chemotherapy (18). However, the different selection criteria determining the optimal approach may be difficult to evaluate, due to the significant heterogeneity among N2 patients.

Previous studies demonstrated that a mediastinal pathological complete response was associated with improved outcomes following resection compared with persistent $\mathrm{N} 2$ disease, with long-term survival rates of patients with persistent N2 disease of $<10-15 \%(6,9)$. In our study, the 5-year survival of patients with persistent N2 disease was $14.6 \%$, which was significantly lower compared with that in patients with $\mathrm{N}$ downstaging $(32.2 \%, \mathrm{P}<0.001)$. This was also consistent with previous data. Therefore, certain studies concluded that appropriate adjuvant therapies may be associated with better outcomes in patients with persistent N2 disease compared with surgery alone $(2,6,7)$.
CT or PET/CT imaging may yield false-positive or false-negative results, as they are based on the morphology or FDG uptake of LNs. Silvestri et al reported the sensitivities of CT and PET/CT for accurate detection of LN metastasis to be 51 and $74 \%$, respectively, with respective specificities of 86 and $85 \%$ (19). Consequently, false-negative results may be obtained with imaging examinations, i.e., unexpected persistent $\mathrm{N} 2$ disease following surgery, even when preoperative imaging suggests $\mathrm{N}$ downstaging. Several authors have reported on the outcomes of unexpected N2 disease $(20,21)$; however, the number of studies investigating unexpected persistent N2 disease is limited. In our study, a total of 348 patients with resectable N2 NSCLC received neoadjuvant chemotherapy. Among these patients, 58 with persistent N2 disease had been considered to be $\mathrm{N}$-downstaged on either $\mathrm{CT}$ or PET/CT prior to surgery $(16.7 \%)$. 
Table III. Multivariate analysis of overall survival.

\begin{tabular}{lcccr}
\hline Variables & Standard error & Hazard ratio & $95 \%$ CI & P-value \\
\hline Grouping & 0.359 & 1.419 & $0.207-0.848$ & 0.016 \\
Predicted FEV1 & 0.247 & 1.680 & $1.036-2.724$ & 0.035 \\
N downstaging & 0.675 & 2.305 & $1.423-5.074$ & 0.013 \\
Skip N2 metastasis & 0.253 & 2.104 & $1.281-3.466$ & 0.003 \\
\hline
\end{tabular}

FEV1; forced expiratory volume in $1 \mathrm{sec}$; CI, confidence interval.

Table IV. Multivariate analysis of disease-free survival.

\begin{tabular}{lcccc}
\hline Variables & Standard error & Hazard ratio & $95 \%$ CI & P-value \\
\hline Grouping & 0.351 & 1.481 & $0.242-0.958$ & 0.037 \\
N downstaging & 0.253 & 2.145 & $1.125-3.523$ & 0.032 \\
\hline
\end{tabular}

CI, confidence interval.

In the present study, we compared the survival outcomes among patients with $\mathrm{N}$ downstaging (pN0-1, group I), those with positive imaging findings and pathological N2 disease (expected persistent N2, group II) and those with negative imaging findings but positive pathological N2 disease (unexpected persistent N2, group III). The 5-year OS rate was 32.2 and $25.9 \%$ in groups I and III, respectively $(\mathrm{P}=0.023)$, whereas the 5 -year DFS rate was 30.1 and $22.4 \%$ in groups I and III, respectively $(\mathrm{P}=0.012)$. OS and DFS in group I were significantly higher compared with those in group III. This may be attributed to patients in group III undergoing more extensive resection compared with those in group I $(\mathrm{P}<0.001)$, although the main reason was the disease stage of the patients in group III. Of note, in our study, there was a significant difference in OS and DFS between groups II and III. Alhough both these groups had persistent N2 disease, different clinical characteristics were associated with different survival. Furthermore, the 5-year OS rate in group III was significantly higher compared with that of patients with persistent $\mathrm{N} 2$ disease (22.4 vs. $14.6 \%, \mathrm{P}=0.033$ ), suggesting that surgery was beneficial for certain patients with persistent $\mathrm{N} 2$ disease.

The rate of objective response to chemotherapy was $75.9 \%(n=264)$. It was previously reported that objective response was observed in $>50 \%$ of cases $(4,5,7,22)$ and certain studies reported that response to chemotherapy was a strong prognostic factor $(4,7,21)$. Accordingly, in our study, grouping and $\mathrm{N}$ downstaging were found to be independent predictive factors associated with OS and DFS, reflecting response to chemotherapy. Mediastinal node downstaging on the resected specimen was a powerful and independent prognostic factor, reflecting the radical resection of systemic disease and effectiveness of chemotherapy. However, this factor was based on postoperative specimen examination and patient selection may be difficult. However, in our study, we demonstrated that patients with unexpected persistent $\mathrm{N} 2$ disease exhibited satisfactory survival rates. Port reported that certain patients may be cured by surgery, particularly in case of previous response to chemotherapy (23).

In patients with persistent $\mathrm{N} 2$ disease, mediastinal LN-related variables, such as the number of N2 levels, may play a role $(3,6)$. In our series, we did not find N2-related variables to be associated with survival. All the patients in our study received neoadjuvant chemotherapy and the variability of protocols and regimens may be a significant prognostic factor. In fact, there was no difference regarding clinical response or pathological nodal status and we did not identify an association between regimen of chemotherapy and survival. In our study, mediastinal regional radiotherapy was performed in patients with persistent $\mathrm{N} 2$ disease, provided they were able to tolerate additional treatments.

Our study had certain limitations. Due to the retrospective nature of the study, some potentially predictive clinical variables were not included; therefore, this study had certain intrinsic drawbacks. Our study was limited by the small patient sample and important information regarding the optimal local treatment modality for patients with persistent N2 disease could not be obtained. Our results suggested that surgery provided a significant survival benefit for patients with unexpected N2 disease and should be first considered in this population. As regards the optimal treatment for patients with expected $\mathrm{N} 2$ disease, our experience suggests that a definitive course of radiotherapy ( $\geq 60 \mathrm{~Gy}$ ) is generally recommended, combined with chemotherapy.

In conclusion, we retrospectively analyzed the clinical and pathological characteristics of NSCLC patients with N2 disease who underwent surgery following neoadjuvant chemotherapy. The survival outcomes were compared according to whether persistent N2 disease was preoperatively expected on the basis of CT or PET/CT following chemotherapy. Patients with unexpected persistent $\mathrm{N} 2$ disease exhibited better survival outcomes compared with those with expected persistent $\mathrm{N} 2$ disease. These findings may be used to select the optimal therapeutic approach to persistent N2 disease. 


\section{References}

1. Groome PA, Bolejack V, Crowley JJ, et al: The IASLC Lung Cancer Staging Project: validation of the proposals for the revision of the T, N, and $\mathrm{M}$ descriptors and consequent stage groupings in the forthcoming (seventh) edition of the TNM classification of malignant tumours. J Thorac Oncol 2: 694-705, 2007.

2. Martini $\mathrm{N}$ and Flehinger BJ: The role of surgery in N2 lung cancer. Surg Clin North Am 67: 1037-1049, 1987.

3. Andre F, Grunenwald D, Pignon JP, Dujon A, Pujol JL, Brichon PY, Brouchet L, Quoix E, Westeel V and Le Chevalier T: Survival of patients with resected N2 non-small-cell lung cancer: Evidence for a subclassification and implications. J Clin Oncol 18: 2981-2989, 2000.

4. Albain KS, Rusch VW, Crowley JJ, et al: Concurrent cisplatin/etoposide plus chest radiotherapy followed by surgery for stages IIIA (N2) and IIIB non-small-cell lung cancer: mature results of Southwest Oncology Group phase II study 8805. J Clin Oncol 13: 1880-1892, 1995.

5. Martini N, Kris MG, Flehinger BJ, et al: Preoperative chemotherapy for stage IIIa (N2) lung cancer: The Sloan-Kettering experience with 136 patients. Ann Thorac Surg 55: 1365-1373, discussion 1373-1374, 1993.

6. Lorent N, De Leyn P, Lievens Y, Verbeken E, Nackaerts K, Dooms C, Van Raemdonck D, Anrys B and Vansteenkiste J; Leuven Lung Cancer Group: Long-term survival of surgically staged IIIA-N2 non-small-cell lung cancer treated with surgical combined modality approach: Analysis of a 7-year prospective experience. Ann Oncol 15: 1645-1653, 2004.

7. Rosell R, Gómez-Codina J, Camps C, et al: A randomized trial comparing preoperative chemotherapy plus surgery with surgery alone in patients with non-small-cell lung cancer. N Engl J Med 330: 153-158, 1994.

8. Pataer A, Kalhor N, Correa AM, et al; University of Texas M. D. Anderson Lung Cancer Collaborative Research Group: Histopathologic response criteria predict survival of patients with resected lung cancer after neoadjuvant chemotherapy. J Thorac Oncol 7: 825-832, 2012.

9. Betticher DC, Hsu Schmitz SF, Tötsch M, et al: Mediastinal lymph node clearance after docetaxel-cisplatin neoadjuvant chemotherapy is prognostic of survival in patients with stage IIIA pN2 non-small-cell lung cancer: a multicenter phase II trial. J Clin Oncol 21: 1752-1759, 2003.

10. Kim YN, Yi CA, Lee KS, et al: A proposal for combined MRI and PET/CT interpretation criteria for preoperative nodal staging in non-small-cell lung cancer. Eur Radiol 22: 1537-1546, 2012.

11. Goldstraw P, Crowley J, Chansky K, et al: The IASLC Lung Cancer Staging Project: proposals for the revision of the TNM stage groupings in the forthcoming (seventh) edition of the TNM Classification of malignant tumours. J Thorac Oncol 2: 706-714, 2007.
12. Miller AB, Hoogstraten B, Staquet M and Winkler A: Reporting results of cancer treatment. Cancer 47: 207-214, 1981.

13. Naruke T, Suemasu K and Ishikawa S: Lymph node mapping and curability at various levels of metastasis in resected lung cancer. J Thorac Cardiovasc Surg 76: 832-839, 1978.

14. Pass HI, Pogrebniak HW, Steinberg SM, Mulshine J and Minna J: Randomized trial of neoadjuvant therapy for lung cancer: Interim analysis. Ann Thorac Surg 53: 992-998, 1992.

15. Roth JA, Fossella F, Komaki R, et al: A randomized trial comparing perioperative chemotherapy and surgery with surgery alone in resectable stage IIIA non-small-cell lung cancer. J Nat Cancer Inst 86: 673-680, 1994.

16. Depierre A, Milleron B, Moro-Sibilot D, et al; French Thoracic Cooperative Group: Preoperative chemotherapy followed by surgery compared with primary surgery in resectable stage I (except T1N0), II, and IIIa non-small-cell lung cancer. J Clin Oncol 20: 247-253, 2002.

17. Nagai K, Tsuchiya R, Mori T, Tada H, Ichinose Y, Koike T and Kato H; Lung Cancer Surgical Study Group of the Japan Clinical Oncology Group: A randomized trial comparing induction chemotherapy followed by surgery with surgery alone for patients with stage IIIA N2 non-small cell lung cancer (JCOG 9209). J Thorac Cardiovasc Surg 125: 254-260, 2003.

18. van Meerbeeck JP, Kramer GW, Van Schil PE, et al; European Organisation for Research and Treatment of Cancer-Lung Cancer Group: Randomized controlled trial of resection versus radiotherapy after induction chemotherapy in stage IIIA-N2 non-small-cell lung cancer. J Natl Cancer Inst 99: 442-450, 2007.

19. Silvestri GA, Gould MK, Margolis ML, et al: Noninvasive staging of non-small cell lung cancer: ACCP evidenced-based clinical practice guidelines (2nd edition). Chest 132 (Suppl 3): 178S-201S, 2007.

20. Kim HK, Choi YS, Kim K, Shim YM, Park K, Ahn YC, Lee KS, Choi JY and Kim J: Outcomes of mediastinoscopy and surgery with or without neoadjuvant therapy in patients with non-small cell lung cancer who are $\mathrm{N} 2$ negative on positron emission tomography and computed tomography. J Thorac Oncol 6: 336-342, 2011.

21. Al-Sarraf N, Aziz R, Gately K, Lucey J, Wilson L, McGovern E and Young V: Pattern and predictors of occult mediastinal lymph node involvement in non-small cell lung cancer patients with negative mediastinal uptake on positron emission tomography. Eur J Cardiothorac Surg 33: 104-109, 2008.

22. Eberhardt W, Wilke H, Stamatis G, et al: Preoperative chemotherapy followed by concurrent chemoradiation therapy based on hyperfractionated accelerated radiotherapy and definitive surgery in locally advanced non-small-cell lung cancer: mature results of a phase II trial. J Clin Oncol 16: 622-634, 1998.

23. Port JL, Korst RJ, Lee PC, et al: Surgical resection for residual N2 disease after induction chemotherapy. Ann Thorac Surg 79: 1686-1690, 2005 